\title{
Assessing the presence of pharmaceuticals in soil and plants irrigated with treated wastewater in Oman
}

\author{
Raya Al-Farsi ${ }^{1} \cdot$ Mushtaque Ahmed $^{1} \cdot$ Ahmed Al-Busaidi $^{1}$ - B. S. Choudri ${ }^{2}$
}

Received: 18 November 2017 / Accepted: 24 February 2018 / Published online: 5 March 2018

(c) The Author(s) 2018. This article is an open access publication

\begin{abstract}
Purpose This study conducted to assess the presence of pharmaceuticals in soils and crops irrigated with treated wastewater in Oman. The study was aimed to evaluate the potential of plant uptake of four commonly used pharmaceuticals in Oman: amoxicillin, sulfamethoxazole, trimethoprim and ibuprofen by radish (Raphanus raphanistrum subsp. sativius) in soil culture. Methods Radish (Raphanus raphanistrum) was selected as a test crop. Liquid chromatography mass spectrometry/mass spectrometry (LC-MS/MS) instrument was used to measure concentrations of pharmaceuticals. Groundwater and treated wastewater were used for irrigation. Additionally, there were two spiked treatments; high-spiked concentration $(5 \mathrm{mg} / \mathrm{l})$ and low-spiked concentration ( $1 \mathrm{mg} / \mathrm{l})$.

Results Results of the study showed that trimethoprim and ibuprofen were not detected in any samples of soil and plant. Sulfamethoxazole accumulated in radish roots for low- and high-spiked treatments. Amoxicillin accumulated in roots with low-spiked- as well as high-spiked treatments. Radish showed the ability to translocate some of the selected pharmaceuticals from soil irrigated with treated wastewater if they are present in sufficient concentrations.

Conclusions Radish showed positive uptake of some selected pharmaceuticals from soil irrigated with treated wastewater with spiked (both high and low) concentration of pharmaceuticals and has the ability to accumulate them in the roots. Pharmaceutical usage and disposal must be given attention to prevent their occurrences in the environment. Furthermore, treated wastewater must be given attention, as it is an important source of water in Oman, which suffers from water shortages.
\end{abstract}

Keywords Pharmaceuticals and personal care products $\cdot$ Treated wastewater $\cdot$ Irrigation $\cdot$ Radish $\cdot$ Translocation $\cdot$ Oman

\section{Introduction}

Pharmaceuticals are defined by World Health Organization (WHO) as synthetic or natural chemicals that can be found in human drugs and veterinary drugs. Pharmaceuticals contain active ingredients that have been designed to have positive effects for human and animal health. Many absorbed drugs in tissues of body would undergo metabolic reactions by microorganisms or enzymes, which may produce other compounds. These compounds excreted through urine or feces and transformed by chemical and physico-chemical factors in water (Mompelat et al. 2009). On the other

B. S. Choudri

bchoudri@squ.edu.om

1 College of Agricultural and Marine Sciences, Sultan Qaboos University, Muscat, Oman

2 Center for Environmental Studies and Research, Sultan Qaboos University, Muscat, Oman hand, significant fractions of the unmetabolized drugs are excreted from the bodies through urine and feces as active compounds. Wastewater treatment systems are not specifically designed to remove pharmaceuticals, as a consequence, pharmaceuticals are partially removed from wastewater during treatment process which contribute to release into the environment (Carballa et al. 2004; Wang et al. 2005; Joss et al. 2006; Chefetz et al. 2008; Kraigher et al. 2008; Islam, 2013; Weng et al. 2014). Pharmaceuticals have been detected in wastewater effluents, biosolids, biosolid-amended soils, runoff from effluent-irrigated fields, surface and groundwater systems receiving treated wastewater (Kolpin et al. 2002; Pedersen et al. 2005; Kinney et al. 2006; Chefetz et al. 2008; Xu et al. 2009; Miller et al. 2016). Investigation of the potentiality of pharmaceuticals to translocate from soil and water into plant tissues were documented in several studies (Christian et al. 2003; Kumar et al. 2005; Boxall et al. 2006; Ji et al. 2012; Wu et al. 2012a, 2013). Plants have the ability to accumulate pharmaceuticals and personal care products 
(PPCPs) in their tissues through root uptake (Dolliver et al. 2007; Wu et al. 2010, 2012a). Wu et al. (2012b) found that spinach and lettuce can uptake some PPCPs from the soil irrigated with treated wastewater. Further, these authors detected trimethoprim in plant tissues with concentrations of $1.1 \pm(0.2-0.4) \mathrm{mg} / \mathrm{g}$ in dry weight in both lettuce and spinach, respectively. Sulfamethoxazole was also detected but in lower concentration than trimethoprim. According to Kumar et al. (2005) concentrations of chlortetracycline and sulfamethazine were measured in corn, lettuce, potato, cabbage and green onion and were found in small range of 2-17 $\mu \mathrm{g} / \mathrm{kg}$, while Dolliver et al. (2007) found that the concentration of sulfamethazine in plant tissue was in the range from 0.1 to $1.2 \mathrm{mg} / \mathrm{kg}$.

In a soil-plant system, the fate, behavior and accumulation of PPCPs in plants may be affected due to the chemical, physical and biological processes in the growing system. Soil characteristics such as soil organic carbon content and ion exchange capacity will influence the mobility of pharmaceuticals, and therefore, their availability in the medium (Chefetz et al. 2008; Herklotz et al. 2010; Eggen et al. 2011). There are different processes resulting in elimination of organic compounds in the environment and to reduce plant uptake of PPCPs. These processes include biotic and abiotic. Sorption process is a significant abiotic process to eliminate PPCPs. Organic materials in soil may alter the surface properties and availability of sites for sorption. High organic content can either inhibit or promote sorption of organic compounds to soil (Miller et al. 2016). In addition, microbes may degrade PPCPs in the root zone (Wu et al. 2014).

Several studies worldwide documented the presence of pharmaceuticals in treated wastewater and soils irrigated with treated wastewater or amended by biosolids (Kinney et al. 2006, 2008; Wu et al. 2012a). Recently, studies have shown that pharmaceutical pollutants are of environmental concern and they are increasing with regard to the occurrences and fate. It is very important to note that exposure to pharmaceuticals through number of routes in values higher than the acceptable daily intake will have detrimental effects (Kümmerer 2008). The continuous disposal of pharmaceuticals into the environment through different ways can cause serious health problems and affect plants and aquatic organisms even at lower concentrations. As a consequence, it is a significant activity to evaluate the presence of the pharmaceuticals in water (Wang et al. 2005). However, in case of Oman, there are few studies undertaken by researchers on use of treated wastewater for irrigation and growing crops on experimental basis including the assessment on qualities of treated wastewater (Baawain et al. 2014a, b, 2015; Jaffar Abdul Khaliq et al. 2017; Abdul Khaliq et al. 2017; AlKhamisi et al. 2017). It is pertinent to mention that based on the literature review in the recent past, there are no studies conducted in Oman on understanding the PPCPs in treated wastewater and its translocation into plant root systems.

This study aims to evaluate and measure the accumulation of four most frequent pharmaceuticals consumed in Oman (SQUH 2016, Personal communication) in soil and plants irrigated with treated wastewater. Target compounds are amoxicillin, sulfamethoxazole, trimethoprim and ibuprofen.

\section{Materials and methods}

\section{Pharmaceuticals and analytical chemistry}

The selected four human drugs (amoxicillin, sulfamethoxazole, trimethoprim and ibuprofen) with purity of $>98 \%$ were purchased from Sigma-Aldrich. The pharmaceutical analysis was done in the Central Analytical \& Applied Research Unit (CAARU) in college of Sciences, Sultan Qaboos University. Liquid chromatography-mass spectrometry/mass spectrometer (LC-MS/MS) is used for the analysis of pharmaceuticals. Standard stock solutions of selected compounds were prepared and injected in the LC-MS/MS to be identified and added to the instrument library. To calculate detection limits, standards were spiked into the appropriate matrix (water) to a level that would produce a signal $<20$ times the baseline noise; detection limits were defined as three times the standard deviation of the signal produced. Each standard was run around six times and the mean was calculated, it was found $0.5 \mu \mathrm{g} / \mathrm{l}$.

\section{Field experiment}

Field experiment and laboratory analysis were conducted to assess the presence of pharmaceuticals in soils and crops irrigated with treated wastewater and to measure their concentration if they are subjected to uptake by plant tissues or accumulate in the soil. The field experiment was conducted at the Agricultural Experimental Station (AES) of Sultan Qaboos University (SQU). Radish (Raphanus raphanistrum) was selected as a test crop because it is consumed raw without cooking and both leaves and roots are eaten. It was grown in shadehouse using pots. Compost of sandy loam soil, cow manure and perlite was used as planting media. The soil used for experiment had $14.91 \%$ organic matter, $7.9 \pm 0.2(\mathrm{pH})$ and $1.4 \pm 0.01 \mathrm{dS} / \mathrm{m}(\mathrm{EC})$. Plants were irrigated according to each plant need with consistent irrigation volume for each plant/replicate set. There were two types of water used for irrigation: groundwater $(\mathrm{GW})$ used as control $(\mathrm{pH}$ : 8.0 and EC: 1.4 $\mathrm{dS} / \mathrm{m})$ and tertiary-treated wastewater (TWW) $(\mathrm{pH}: 8.1$ and EC: 0.65 ). Additionally, two spiked treatment were prepared from $\mathrm{dS} / \mathrm{m}$ TWW and mixed pharmaceuticals; treated wastewater with low concentration of mixed 
pharmaceuticals (TW $+\mathrm{LC}$ ) and treated wastewater with high concentration of mixed pharmaceuticals $(\mathrm{TW}+\mathrm{HC})$. The treatments were called according to the water type used for irrigation. There were a total of 16 pots $(18 \mathrm{~cm}$ diameter $* 17 \mathrm{~cm}$ height) filled with $3 \mathrm{~kg}$ of soil. Each treatment contained four replicate containers with three plants each. The spiked water with mix of selected pharmaceuticals was changed for each time of irrigation to minimize the error due to the metabolism of pharmaceuticals in the water and it was used few minutes after spiking. The concentrations of pharmaceuticals were selected to be high considering soil as a planting media, which may reduce the availability of compounds for plant uptake due to the biotic and abiotic process in the soil-plant system. Several process and factors will play role in translocation and uptake of pharmaceuticals and may affect the availability of compounds to the plants. Moreover, the artificially high spiked levels of pharmaceuticals were used in the study to enable analysis. Two concentrations of pharmaceuticals were prepared with TWW. $1 \mathrm{mg}$ of each compound (amoxicillin, ibuprofen, sulfamethoxazole, and trimethoprim) was added to 1 liter of TWW to prepare low concentration of spiked water (TW + LC) mixture. Hence, the concentration of each compound in that case was $1 \mathrm{mg} / \mathrm{l} .5 \mathrm{mg}$ of each compound was added to $11 \mathrm{of}$ TWW to prepare high concentration of spiked water $(\mathrm{TW}+\mathrm{HC})$ mixture. The concentration of each compound in that case was $5 \mathrm{mg} / \mathrm{l}$. Plants received total amount of $7.5 \mathrm{mg}$ from each compounds as low concentration $(\mathrm{TW}+\mathrm{LC})$ and $37.5 \mathrm{mg}$ as high concentration ( TW $+\mathrm{HC}$ ) for 33 days of growth. All plants were allowed to reach maturity before harvesting. Chlorophyll and leaf area were measured for all plants. The measurements were recorded once a week for each pot. Additionally, radish biomass (roots and shoots) was recorded after harvesting and soil organic matter content was also determined. There were no attempts to collect the leachates from the pots after irrigation.

\section{Field experiment layout}

The experimental layout for the radish replicates of the irrigated pots are shown in Fig. 1. Four replicates were set and only three were used to collect the samples. One pot was kept as stock for the replicates.

\section{Sample preparation}

For sampling, soil samples were homogenized and crushed with mortar and pestle, then sieved in a $2 \mathrm{~mm}$ sieve. Three whole plants were harvested from each pot and combined as one single sample. Samples were transported to the laboratory immediately and separated into roots and leaves. Plant samples were washed using tap water and then rinsed with distilled water to remove the adhering soil. The weights of fresh plants were recorded. They were chopped into small pieces and stored in the freezer under 40 to $80{ }^{\circ} \mathrm{C}$ for $2 \mathrm{~h}$ to 1 day. Then, they were freeze-dried for 3-4 days to remove residual water using Labconco system. The dried samples were ground into a fine powder using a coffee grinder with stainless steel grinding chamber. All samples were stored under $20^{\circ} \mathrm{C}$ until the process of extraction.

\section{Sample extraction}

An effective preparation method for plant sample extraction was developed by (Wu et al. 2012a). This method was modified to extract the selected compounds from soil and radish samples. Weight of about $0.2 \mathrm{~g}$ of sample was transferred in a $50 \mathrm{ml}$ of glass centrifuge tube. Samples were spiked with deuterated pharmaceutical standards as recovery surrogates. Around $10 \mathrm{ml}$ of MTBE (Methyl tertiary-butyl ether) was added and extracted in a sonication bath for $20 \mathrm{~min}$ and centrifuged for $3 \mathrm{~min}$ at $3600 \mathrm{rpm}$. The supernatant was decanted in a $40 \mathrm{ml}$ glass vial. $10 \mathrm{ml}$ of acetonitrile was added to the residual and extracted again in a sonication bath
Fig. 1 The layout of the field experiment

for $20 \mathrm{~min}$ and centrifuged for $3 \mathrm{~min}$ at $3600 \mathrm{rpm}$, then it was transferred to the same $40 \mathrm{ml}$ glass vial. The combined extract dried under nitrogen gas at $30-40{ }^{\circ} \mathrm{C}$ using sample concentrator instrument. Then, it was recovered with $1 \mathrm{ml}$ of methanol, and diluted with $20 \mathrm{ml}$ of ultrapure water. The aqueous sample solutions were loaded under gravity onto a C18 cartridge using a syringe. Air vacuum can also be used to pass the sample through the cartridge by adjusting one drop per second. The cartridge was preconditioned with 3-6 $\mathrm{ml}$ of methanol and then with 3-6 $\mathrm{ml}$ of ultrapure water before loading the sample. Finally, the analytes were eluted under gravity with $2 \mathrm{ml}$ of methanol and the elution was injected into liquid chromatography-mass spectrometry/ mass spectrometry (LC/MS/MS) for detection.

\section{Results and discussion}

\section{Soil samples}

At the end of the experiment, the values of $\mathrm{pH}$ for soil samples were slightly alkaline in the range of $7.9 \pm 0.2-7.8 \pm 0.1$. EC values for all soil samples were low to medium in the range of $0.64 \pm 0.17 \mathrm{dS} / \mathrm{m}$ to $1.34 \pm 0.14 \mathrm{dS} / \mathrm{m}$. The value of $\mathrm{pH}$ is negatively correlated to the sorption coefficient of organic compounds and acidic condition promote accumulation in the soil (Zheng et al. 2013).

The organic matter content of soil in all treatments showed similar values in the range of $14.62 \% \pm 3.62$ to $14.73 \% \pm 1.05$. Therefore, no effects can be assumed on the organic matter content in soils irrigated with treated wastewater even with high concentrations of pharmaceuticals. The organic matter content was found in high levels because the compost containing high amount of cow manure which contributed to increase in organic matter content and other nutrients and minerals in the soil. On the other hand, the organic matter in the soil can affect the availability of pharmaceuticals for plant uptake. According to Miller et al. (2016) organic materials in soil may alter the surface properties and availability of sites for sorption. Then, they can either inhibit or promote sorption of organic compounds to soil. High organic content in soil may result in decreasing sorption of pharmaceuticals to soil particles and making them available for plant uptake or leaching deep in soil layers (Miller et al. 2016).

\section{Pharmaceuticals in soil samples}

There was no detection of any of the selected compounds in all soil samples. The disappearance of pharmaceuticals was assumed due to four main reasons; (1) organic compounds can be degraded by biotic and non-biotic process in soil, (2) their degradation was accelerated because of their small biological half-life, (3) high level of organic matter content may play significant role in pharmaceutical sorption to soil particles, (4) complete uptake of pharmaceuticals by plant parts but the non-detectability or low detected levels of those compounds in some plant parts for spiked treatments indicated absence of them from soil. Therefore, there was some uncertainty on the disappearance of those pharmaceuticals from soil. It is also possible that the pharmaceutical leaching beyond the sampling depth but the experiment was not designed to collect the leachates.

The results of this study for soil samples mostly agreed with other studies for the same compounds using soil as planting media but with different crops and experimental conditions. The four selected compounds were not detected in soil samples as found in different studies: trimethoprim and amoxicillin (Boxall et al. 2006), ibuprofen (Winker et al. 2010; Malchi et al. 2014) sulfamethoxazole (Christian et al. 2003). While, Malchi et al. (2014) detected sulfamethoxazole in soil samples.

\section{Radish samples}

\section{Plant development and health}

In general, a negative effect on plant growth was measured as reduced in the quality and quantity of radish biomass showing the most pronounced effect for treatments spiked with high concentration of mixed pharmaceuticals. Moreover, all plants were attacked by pests such as whiteflies and aphids, the spiked treatments showed less resistance even after using the pesticides to control the pests. The plants in the treatment of high-spiked concentration showed the lowest resistance and some plants lost the mature leaves and few of them did not survive. Plants irrigated with groundwater and treated wastewater were found to be healthy and resisted pests that were exposed to (Fig. 2).

Radish leaves showed normal development for all treatments during growth period except for the spiked treated wastewater treatment. In the last stage of growth, some plants in the spiked treatments declined. In high concentration of spiked pharmaceuticals, some plants died and some of them lost mature leaves. Hence, leaf area was decreasing in that period of growth. The negative effects observed at the high concentrations of pharmaceuticals could be related to plant efficiency in the pharmaceutical uptake at $\mathrm{mg} / \mathrm{kg}$ level. Pharmaceuticals may inhibit transportation of essential nutrients for growth and toxicity of some organic compounds or elements may cause plant stress and affect the normal growth of plants (Miller et al. 2016). Chlorophyll content showed good and nearly similar values for all treatments in the first week of growth, but it started slightly to decline after reaching maturity. Chlorophyll content of 


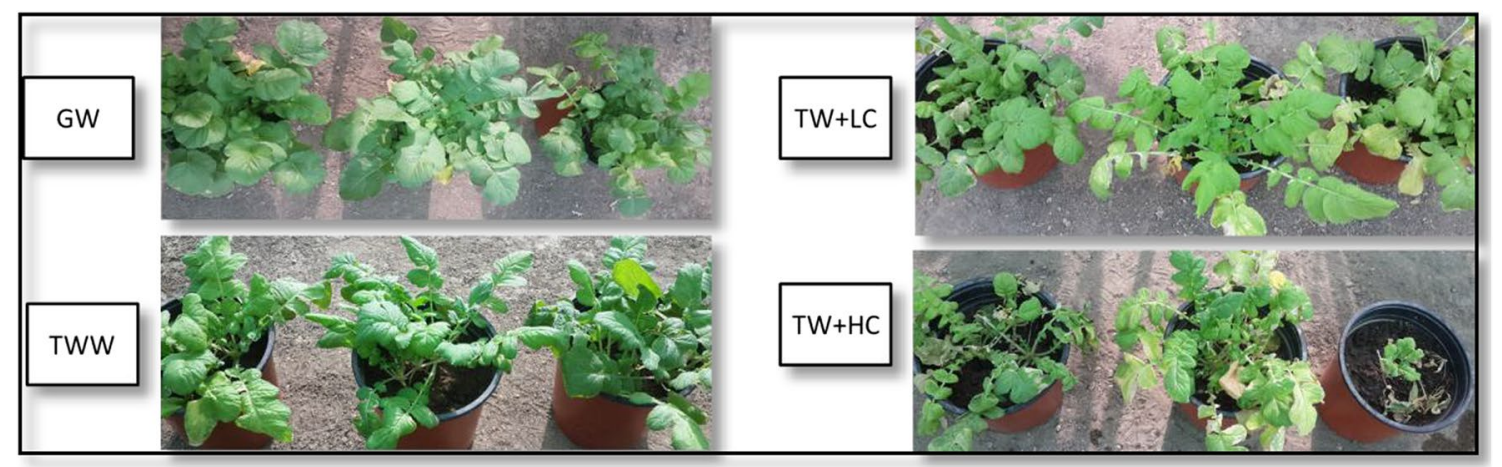

Fig. 2 Qualitative observation of plant health of the four different treatments, GW: groundwater, TWW: treated wastewater, TW + LC: treated wastewater with low concentration of mixed pharmaceuticals

plants in spiked treatments showed more decrease than other two treatments.

Plants grown using groundwater treatments showed the highest biomass for both roots and shoots. Plants irrigated with treated wastewater also showed good biomass for shoots and roots. Plants irrigated with treated wastewater spiked with low concentration of mixed pharmaceuticals showed similar biomass as treated wastewater treatment. While plants irrigated with treated wastewater of highspiked concentration showed to have the smallest biomass for both roots and shoots. The loss in leaves of plants and death of other plants in some pots caused the decrease in biomass. Furthermore, the plant roots of high-spiked concentration treatment showed very small biomass.

\section{Pharmaceuticals in plant samples}

The complex matrix of plant tissue makes it difficult in the determination of some organic compounds. Two compounds from the selected pharmaceuticals were detected in shoots and roots of radish (sulfamethoxazole and amoxicillin). Trimethoprim and ibuprofen were not detected in both plant parts from all treatments, indicating no accumulation or translocation of them into the plant tissues. This was likely because of their small half-lives in the medium (human body, soil, water and other environmental medium) or degradation process by biotic and non-biotic process. Furthermore, the high level of organic matter and alkaline condition in soil decreased their availability in plant soil system. These results did not agree with the study of Boxall et al. (2006), they detected trimethoprim in lettuce and carrot tissue of concentration 5.3-6 $\mu \mathrm{g} / \mathrm{kg}$ and Goldstein et al. (2014) detected ibuprofen in tomato and cucumber crops. The accumulation rate in plants of high-concentration-spiked treatment was lower than the plants of low-concentration-spiked treatment and that is because of the small root biomass of plants of high-concentration-spiked treatment; which and TW + HC: treated wastewater with high concentration of mixed pharmaceuticals

make small surface area and decrease the available sites for accumulation.

\section{Accumulation in the roots}

Analysis of radish roots showed positive detection of pharmaceuticals in both spiked treatments for three compounds of selected pharmaceuticals. Sulfamethoxazole was detected in the roots of both spiked treatments of low $(1 \mathrm{mg} / \mathrm{l})$ and high $(5 \mathrm{mg} / \mathrm{l})$ concentrations. It was found $1.06 \pm 0.63 \mathrm{mg} / \mathrm{kg}$ and $1.89 \pm 0.68 \mathrm{mg} / \mathrm{kg}$ for low- and high-spiked concentrations, respectively. Amoxicillin was also detected in roots of the spiked treatments but in lower concentrations than sulfamethoxazole. It was found to be $0.81 \pm 1.41 \mathrm{mg} / \mathrm{kg}$ in low spiked treatment and $0.91 \pm 1.26 \mathrm{mg} / \mathrm{kg}$ in high-spiked treatment (Fig. 2). Accumulation rate could be calculated since to the total amount of plants and soil received was 7.5 and $37.5 \mathrm{mg}$ for low- and high-spiked concentration treatments, respectively. The accumulation and translocation rates ware calculated based on the relationship: [(detected concentration of the compound/the total amount received by plant of the compound) $* 100$ ]. Around $14 \%$ of sulfamethoxazole was accumulated in the roots of low-concentration-spiked treatment, while $5 \%$ of it was accumulated in the roots of plants received high concentration of mixed pharmaceuticals. About that $10.8 \%$ of amoxicillin was accumulated in plant roots using the treatment of low-spiked concentration, while $2.4 \%$ was accumulated on the roots of plants received high concentration of mixed pharmaceuticals.

\section{Translocation to the leaves}

The translocation of pharmaceuticals occurred if there was sufficient concentration of them in the media. Sulfamethoxazole translocated from roots to the leaves was found in plants irrigated with treated wastewater spiked with high concentration of mix pharmaceuticals (Fig. 3). The translocation 


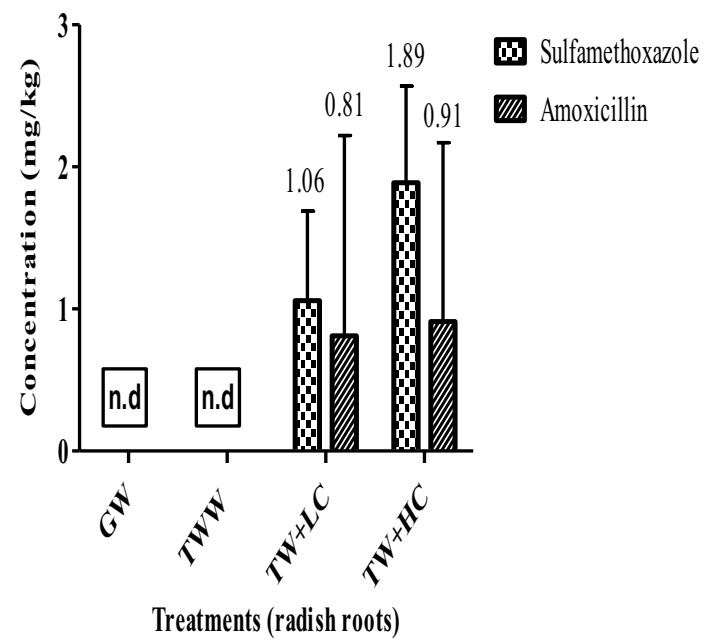

Fig. 3 Detected concentrations of pharmaceuticals accumulated in radish roots and that were translocated to the radish leaves (n.d: not detected), the results were calculated for three replicate samples and presented as mean values, GW: groundwater, TWW: treated waste-

of sulfamethoxazole and amoxicillin were $6.04 \pm 3.56$ and $1.73 \pm 0.63 \mathrm{mg} / \mathrm{kg}$, respectively. The transferred rate of sulfamethoxazole into the leaves was $16 \%$, while $4.6 \%$ of amoxicillin was transferred to the radish leaves.

The translocation and accumulation rate of sulfamethoxazole was higher than amoxicillin in both treatments. Sulfamethoxazole has higher biological half-life in the available medium (human body, soil, water and other environmental medium) by ten times than amoxicillin, which make it available for a longer time, and then it can accumulate and transfer in higher rate. The other percentage of them were assumed to be degraded in the soil or leached deep. The leachate was too small in amount and it was not collected after irrigation. The detected concentrations of selected pharmaceuticals in both roots and shoots showed that radish has the potentiality to uptake and transfer high levels of those pharmaceuticals, which may be available in planting soil. The summary of the results is presented in Table 1.

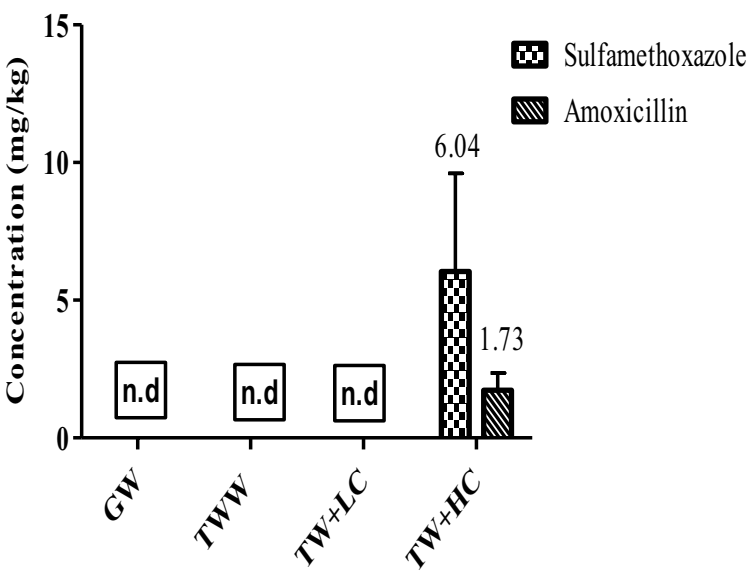

Treatments (radish leaves)

water, $\mathrm{TW}+\mathrm{LC}$ : treated wastewater with low concentration of mixed pharmaceuticals and TW + HC: treated wastewater with high concentration of mixed pharmaceuticals

Results obtained in this experiment did not agree with the findings of Boxall et al. (2006), amoxicillin was not detected in the test crops (lettuce and carrot). While the study of Malchi et al. (2014) agreed with this study for sulfamethoxazole as it was detected in the roots of sweet potatoes and carrots but in small concentrations $(0.05-0.24 \mathrm{ng} / \mathrm{g})$.

\section{Conclusion}

Radish showed positive uptake of some selected pharmaceuticals from soil irrigated by treated wastewater with spiked concentration of pharmaceuticals and had the ability to accumulate them in the roots. It was found that sulfamethoxazole accumulated in radish roots at $1.06 \pm 0.63$ and $1.89 \pm 0.68 \mathrm{mg} / \mathrm{kg}$ for low- and high-spiked concentrations, respectively. Amoxicillin accumulated in roots in concentrations of $0.81 \pm 1.41 \mathrm{mg} / \mathrm{kg}$ in low-spiked treatment and

Table 1 Summary of the detected concentrations of selected pharmaceuticals in radish leaves and roots

\begin{tabular}{|c|c|c|c|c|c|c|c|c|}
\hline \multirow[t]{3}{*}{ Treatment compounds } & \multicolumn{4}{|c|}{ Accumulation in the roots } & \multicolumn{4}{|c|}{ Translocation to the leaves } \\
\hline & \multicolumn{2}{|c|}{ Concentrations (mg/kg) } & \multicolumn{2}{|c|}{$\%$ of total exposed amount } & \multicolumn{2}{|c|}{ Concentrations (mg/kg) } & \multicolumn{2}{|c|}{$\begin{array}{l}\% \text { of total exposed } \\
\text { amount }\end{array}$} \\
\hline & $\mathrm{TW}+\mathrm{LC}$ & $\mathrm{TW}+\mathrm{HC}$ & $\mathrm{TW}+\mathrm{LC}$ & $\mathrm{TW}+\mathrm{HC}$ & $\mathrm{TW}+\mathrm{LC}$ & $\mathrm{TW}+\mathrm{HC}$ & $\mathrm{TW}+\mathrm{LC}$ & $\mathrm{TW}+\mathrm{HC}$ \\
\hline Amoxicillin & $0.81 \pm 1.41$ & $0.91 \pm 1.26$ & 10.8 & 2.4 & n.d & $1.73 \pm 0.63$ & n.d & 4.6 \\
\hline Sulfamethoxazole & $1.06 \pm 0.63$ & $1.89 \pm 0.68$ & 14 & 5 & n.d & $6.04 \pm 3.56$ & n.d & 16 \\
\hline
\end{tabular}

The results were calculated for three replicate samples and presented as mean values, groundwater (GW) and treated wastewater (TWW) treatments were free from the four pharmaceuticals. Ibuprofen and trimethoprim were not detected in the spiked treatments. TW + LC: treated wastewater with low concentration of mixed pharmaceuticals and $\mathrm{TW}+\mathrm{HC}$ : treated wastewater with high concentration of mixed pharmaceuticals, n.d not detected 
$0.91 \pm 1.26 \mathrm{mg} / \mathrm{kg}$ in high-spiked treatment. Furthermore, radish has the ability to translocate selected pharmaceuticals (sulfamethoxazole and amoxicillin) from soil irrigated with treated wastewater with spiked concentration of pharmaceuticals if they are present in sufficient concentrations. Soil degraded the selected pharmaceuticals by biotic and nonbiotic process. Therefore, pharmaceutical usage and disposal must be given attention to prevent their occurrences in the environment. Furthermore, treated wastewater must be given attention, as it is an important source of water in Oman and there are plans to supply treated wastewater for irrigation to cater the shortages in availability of water resources.

Open Access This article is distributed under the terms of the Creative Commons Attribution 4.0 International License (http://creativeco mmons.org/licenses/by/4.0/), which permits unrestricted use, distribution, and reproduction in any medium, provided you give appropriate credit to the original author(s) and the source, provide a link to the Creative Commons license, and indicate if changes were made.

\section{References}

Abdul Khaliq SJ, Al-Busaidi A, Ahmed M, Al-Wardy M, Agrama H, Choudri BS (2017) The effect of municipal sewage sludge on the quality of soil and crops. Int J Recycl Org Waste Agric 6(4):289299. https://doi.org/10.1007/s40093-017-0176-4

Alkhamisi SA, Ahmed M, Al-Wardy M, Prathapar SA, Choudri BS (2017) Effect of reclaimed water irrigation on yield attributes and chemical composition of wheat (Triticum aestivum), cowpea (Vigna sinensis), and maize (Zea mays) in rotation. Irrig Sci 35(2):87-98. https://doi.org/10.1007/s00271-016-0522-8

Baawain MS, Al-Omairi A, Choudri BS (2014a) Characterization of domestic wastewater treatment in Oman from three different regions and current implications of treated effluent. Environ Monit Assess 186(5):2701-2716. https://doi.org/10.1007/s1066 1-013-3572-x

Baawain MS, Al-Jabri M, Choudri BS (2014b) Characterization of domestic wastewater sludge in Oman from three different regions and recommendations for alternative reuse applications Iran. J Public Health 43(2):168-177

Baawain MS, Al-Jabri M, Choudri BS (2015) Characterization of industrial wastewater sludge in Oman from three different regions and recommendations for alternate reuse applications Iran. J Public Health 44(11):1473-1481

Boxall AB, Johnson P, Smith EJ, Sinclair CJ, Stutt E, Levy LS (2006) Uptake of veterinary medicines from soils into plants. J Agric Food Chem 54(6):2288-2297. https://doi.org/10.1021/jf053041t

Carballa M, Omil F, Lema JM, Llompart MA, García-Jares C, Rodríguez I, Gomez M, Ternes T (2004) Behavior of pharmaceuticals, cosmetics and hormones in a sewage treatment plant. Water Res 38(12):2918-2926. https://doi.org/10.1016/j.watre s.2004.03.029

Chefetz B, Mualem T, Ben-Ari J (2008) Sorption and mobility of pharmaceutical compounds in soil irrigated with reclaimed wastewater. Chemosp 73(8):1335-1343. https://doi.org/10.1016/j.chemo sphere.2008.06.070

Christian T, Schneider RJ, Färber HA, Skutlarek D, Meyer MT, Goldbach HE (2003) Determination of antibiotic residues in manure, soil, and surface waters. Clean Soil Air Water 31(1):36-44
Dolliver H, Kumar K, Gupta S (2007) Sulfamethazine uptake by plants from manure-amended soil. J Environ Qual 36(4):1224-1230. https://doi.org/10.2134/jeq2006.0266

Eggen T, Asp TN, Grave K, Hormazabal V (2011) Uptake and translocation of metformin, ciprofloxacin and narasin in forage-and crop plants. Chemosph 85(1):26-33. https://doi.org/10.1016/j.chemo sphere.2011.06.041

Goldstein M, Shenker M, Chefetz B (2014) Insights into the uptake processes of wastewater-borne pharmaceuticals by vegetables. Environ Sci Technol 48(10):5593-5600. https://doi.org/10.1021/ es5008615

Herklotz PA, Gurung P, Heuvel BV, Kinney CA (2010) Uptake of human pharmaceuticals by plants grown under hydroponic conditions. Chemosph 78(11):1416-1421

Islam G (2013) Impact of tetracycline on microbial communities in the secondary treatment process of wastewater treatment systems. Master's Thesis, Ryerson University, Toronto, ON, Canada

Jaffar Abdul Khaliq S, Ahmed M, Al-Wardy M, Al-Busaidi A, Choudri BS (2017) Wastewater and sludge management and research in Oman: an overview. J Air Waste Manag Assoc 67(3):267-278. https://doi.org/10.1080/10962247.2016.1243595

Ji X, Shen Q, Liu F, Ma J, Xu G, Wang Y, Wu M (2012) Antibiotic resistance gene abundances associated with antibiotics and heavy metals in animal manures and agricultural soils adjacent to feedlots in Shanghai; China. J Hazard Materials. https://doi. org/10.1016/j.jhazmat.2012.07.040

Joss A, Zabczynski S, Göbel A, Hoffmann B, Löffler D, McArdell CS, Ternes TA, Thomsen A, Siegrist H (2006) Biological degradation of pharmaceuticals in municipal wastewater treatment: proposing a classification scheme. Water Res 40(8):1686-1696. https://doi. org/10.1016/j.watres.2006.02.014

Kinney CA, Furlong ET, Werner SL, Cahill JD (2006) Presence and distribution of wastewater-derived pharmaceuticals in soil irrigated with reclaimed water. Environ Toxicol Chem 25(2):317326. https://doi.org/10.1897/05-187R.1

Kinney CA, Furlong ET, Kolpin DW, Burkhardt MR, Zaugg SD, Werner SL, Bossio JP, Benotti MJ (2008) Bioaccumulation of pharmaceuticals and other anthropogenic waste indicators in earthworms from agricultural soil amended with biosolid or swine manure. Environ Sci Technol 42(6):1863-1870. https://doi.org/10.1021/ es702304c

Kolpin DW, Furlong ET, Meyer MT, Thurman EM, Zaugg SD, Barber LB, Buxton HT (2002) Pharmaceuticals, hormones, and other organic wastewater contaminants in US streams, 1999-2000: a national reconnaissance. Environ Sci Technol 36(6):1202-1211. https://doi.org/10.1021/es011055j

Kraigher B, Kosjek T, Heath E, Kompare B, Mandic-Mulec I (2008) Influence of pharmaceutical residues on the structure of activated sludge bacterial communities in wastewater treatment bioreactors. Water Res 42(17):4578-4588. https://doi.org/10.1016/j.watre s.2008.08.006

Kumar K, Gupta S, Baidoo S, Chander Y, Rosen C (2005) Antibiotic uptake by plants from soil fertilized with animal manure. J Environ Qual 34(6):2082-2085. https://doi.org/10.2134/jeq2005.0026

Kümmerer K (2008) Pharmaceuticals in the environment-a brief summary. In: Kümmerer K (ed) Pharmaceuticals in the environment. Springer, Berlin, pp 3-21. https://doi.org/10.1007/978-3540-74664-5-1

Malchi T, Maor Y, Tadmor G, Shenker M, Chefetz B (2014) Irrigation of root vegetables with treated wastewater: evaluating uptake of pharmaceuticals and the associated human health risks. Environ Sci Technol 48(16):9325-9333. https://doi.org/10.1021/es501 7894

Miller EL, Nason SL, Karthikeyan K, Pedersen JA (2016) Root uptake of pharmaceuticals and personal care product ingredients. Environ 
Sci Technol 50(2):525-541. https://doi.org/10.1021/acs.est.5b015 46

Mompelat S, Le Bot B, Thomas O (2009) Occurrence and fate of pharmaceutical products and by-products, from resource to drinking water. Environ Int 35(5):803-814. https://doi.org/10.1016/j.envin t.2008.10.008

Pedersen JA, Soliman M, Suffet I (2005) Human pharmaceuticals, hormones, and personal care product ingredients in runoff from agricultural fields irrigated with treated wastewater. J Agric Food Chem 53(5):1625-1632. https://doi.org/10.1021/jf049228m

Wang Y, Hu W, Cao Z, Fu X, Zhu T (2005) Occurrence of endocrinedisrupting compounds in reclaimed water from Tianjin, China. Anal Bioanal Chem 383(5):857-863

Weng S, Sun P, Ben W, Huang CH, Lee LT, Blatchley ER III (2014) The presence of pharmaceuticals and personal care products in swimming pools. Environ Sci Technol Lett 1(12):495-498. https ://doi.org/10.1021/ez5003133

Winker M, Clemens J, Reich M, Gulyas H, Otterpohl R (2010) Ryegrass uptake of carbamazepine and ibuprofen applied by urine fertilization. Sci of The Total Environ 408(8):1902-1908. https:// doi.org/10.1016/j.scitotenv.2010.01.028

Wu C, Spongberg AL, Witter JD, Fang M, Czajkowski KP (2010) Uptake of pharmaceutical and personal care products by soybean plants from soils applied with biosolids and irrigated with contaminated water. Environ Sci Technol 44(16):6157-6161. https:// doi.org/10.1021/es1011115

Wu C, Spongberg AL, Witter JD, Sridhar BM (2012a) Transfer of wastewater associated pharmaceuticals and personal care products to crop plants from biosolids treated soil. Ecotoxicol Environ Saf 85:104-109

Wu X, Conkle JL, Gan J (2012b) Multi-residue determination of pharmaceutical and personal care products in vegetables. J Chromatogr A 1254:78-86. https://doi.org/10.1016/j.chroma.2012.07.041

Wu X, Ernst F, Conkle JL, Gan J (2013) Comparative uptake and translocation of pharmaceutical and personal care products (PPCPs) by common vegetables. Environ Int 60:15-22. https:// doi.org/10.1016/j.envint.2013.07.015

Wu X, Conkle JL, Ernst F, Gan J (2014) Treated wastewater irrigation: uptake of pharmaceutical and personal care products by common vegetables under field conditions. Environ Sci Technol 48(19):11286-11293. https://doi.org/10.1021/es502868k

Xu J, Wu L, Chen W, Jiang P, Chang ACS (2009) Pharmaceuticals and personal care products (PPCPs), and endocrine disrupting compounds (EDCs) in runoff from a potato field irrigated with treated wastewater in southern California. J Health Sci 55(2):306-310

Zheng H, Wang Z, Zhao J, Herbert S, Xing B (2013) Sorption of antibiotic sulfamethoxazole varies with biochars produced at different temperatures. Environ Pollut 181:60-67. https://doi.org/10.1016/j. envpol.2013.05.056

Publisher's Note Springer Nature remains neutral with regard to urisdictional claims in published maps and institutional affiliations. 